In the first place, a material had to be provided which would admit of being engraved rapidly without burr or chipping, and would, without further preparation, serve as a mould for type metal. Secondly, drill pantagraphs had to be adapted to engrave the lines, and to be furnished with a gauge so as to vary their depth at pleasure.

The actual process is as follows:-The outline of the land is kept standing, and the composition is run in a mould bearing this outline on one face. The block, which is now an outline chart of the British Islands, is then placed under the pantagraph drill, which reduces the original drawing, furnished from the Meteorological Office, to one-fourth. The barograms and wind-arrows are put on direct from the drawing, the figures and words by means of templates, in order to ensure uniformity in the type.

The instant the block is engraved it is ready to be stereotyped, and then it is a simple matter to adapt it in the usual manner to the cylinder of the machine.

The initiative in this new method of weather iliustration is due to Mr. Francis Galton, and the practical details have been carried out by Messis. Shanks and Johnson, of the Patent Type Founding Company.

It is hardly necessary to allude to the value of such charts as these as a means of leading the public to gain some idea of the laws which govern our weather changes. As soon as they appear in our afternoon papers, we may hope for a more intelligent comprehension of the difficulties which beset any attempt to foretell the weather of thcse islands for the space of even twenty-four hours.

We may safely say that with these charts we have not seen the end of weather illustration, which was set on foot more than four years ago by Sir W. Mitchell in the Slipping Gazette, and has been continued daily; but whatcver improvements may hereafter be introduced in the process, it must be remembered that the credit of breaking the egg is due to the gentleman we have named.

\section{THE ECLIPSE EXPEDITION}

THE local arrangements for the Eclipse parties, to which we referred last week, have, we now know, beein altered in the cases both of the Bay of Bengal and Siam parties.

With regard to the former, letters received from Galle, writien shortly before the sailing of the Enicrprise (which had arrived at that port from Calcutta with Capt. Waterhouse, Profs. Tacchini and Pedler, and three photographic assistants on board), state that it had been determined to give up Mergui, first because the accommodation there was doubtful, and secondly, because, in the opinion of those best informed, a cloudless sky at Camorta was almost a certainty. Hence there will be two strong parties on Camorta itself as widely separated as possible ; and here, it will be remembered, the totality is longer than at any other station, being no less than $4 \mathrm{~m} .27 \mathrm{~s}$. at Kaikul.

The Indian Government had been careful to prepare huts for observatories on this island before even the Enterprise had left Calcutta; and as certain parts of it are known to be malarious, all the observers will sleep on board the steamer.

With regard to the Siam party, a Reuter's telegram, dated Singapore, April 8 , shows that this party, instead of going direct to Chulai Point, has gone to Bangkok; and it would appear from the telegram that the observatories were being erected at some spot nearer Bangkok than the proposed station.

\section{NOTES}

IT is with the greatest satisfaction we record that on Tuesday Mr. James Dewar, Demonstrator of Chemistry in the University of Edinburgh, was elected to the Cambridge Jacksonian. Professor. ship; all the other candidates having withdrawn. As our readers know, Mr. Dewar has alrealy done excellent work, and is so widely known as a gifted investigator as well as a first-rate teacher, that his presence at Cambridge will be a great gain, not only to that University, but to English Science.

THE Alert and Discovery, the two ships destined for the Arctic Expedition, are to be commissioned to-day. In addition to the naturalists specially appointed, Captain Mark. ham and several of the lieutenants and sub-lieutenants have been undergoing special instruction in the instruments they will have to use-astronomical instruments, pendulums; magneto. meters, and spectroscopes.

AT Monday's sitting of the French Academy of Sciences, a letter was read from M. Puiseux, giving a résumé of his calcula. tion for the solar parallax, founded on the recent Transit observations. M. Puiseux has made a comparison between the St. Paul Transit observations by Mouchez, and those of Pekin by Fleuriais. The exact amount of the parallax is $8.879^{\prime \prime}$. Both observers had 6-inch refractors. The comparison of the results obtained by Fleuriais and another observer at St. Paul with a 4 -inch refractor gives $8.84^{\prime \prime}$. M. Puiseux, in computing the sources of error, states in his letter that the error cannot be more than ${ }_{1}^{\frac{1}{0}} \frac{1}{0}$ of a second, by supposing the error to be two or three seconds of time for the moment of transit. M. Puiseux spoke briefly in support of the opinion expressed in his letter.

THE following from the Kolniscke Zeitung of March 25, in reference to the recently invented "hardened glass," will be interesting :-According to the reports of Pliny, Petronius, and Dion Cassius, a man is said to have invented the making of flexible and malleable glass in the time of the Emperor Tiberius. The happy inventor-some call him a glass-maker, others an architectbrought to the Emperor a vase made from the new glass, with the hope of a rich reward. The Emperor, fearing that the ne: w material might cause a decrease in the value of gold and silver, thre w the vase to the ground in a passion. The vasc, however, did not break, but was only bent like metal, and the inventor at once repaired the damage done with a little hammer; whereupon the Emperor had the poor fellow killed on the spot, so that he should not tell his dangerous secret to anyone. For years people have lost themselves in conjectures of what material this malleable glass might have been ; some thought it was aluminium, others that it was melied chloride of silver; none, however, were certain. From various quarters the invention is now announced of a new glass which refists blows and the action of fire. Last autumn a company was formed at Bourg, in France, with a capital of $1,200,000$ francs, for the working of an invention in this line, made by a M. de la Bastie. The German Glass-makers' Union communicated with this company with a view to purchase the invention, but this remained without further consequences, as the demands of the company were exorbitant. In the meantime it had been found that the elasticity was given to the glass by dipping the same, while it is heated to a half liquid state, into a hermetically closed bath of oil or fat, substances therefore which meit far below the boiling-point of water. In Silesia, where repeated experiments have tested the qualities of the De la Bastie glass, another new glass was invented a few days ago, by Herren Lubisch and Riederer, in Count Solm's glass-works, Andreashiitte, at Klitschdorf, near Bunzlau. This glasi, which the inventors call "metal glass," is so hard, that when, a pane lies on the ground and a leaden ball of forty grammes weight falls upon it from an elevation of twelve feet, it receives not the slightest impression; nor is it in the least affected when dipped whilst red-hot into cold water. Window panes, lamp cylinders, and other articles of domestic use made from this metal glass, can therefore almost be denoted as unbreakable. 